\title{
SOME OBSERVATIONS ON THE ELECTROENCEPHALOGRAM IN CEREBRAL TUMOURS
}

\author{
BY \\ J. H. D. MILLAR \\ From the Department of Neurology, Royal Victoria Hospital, Belfast
}

The usefulness of the E.E.G. in the localization of intracranial space-occupying lesions is now generally accepted. High amplitude slow waves in cases of intracranial tumours were first observed by Berger (1931). The tumour itself is electrically inert and the slow waves arise from partially damaged surrounding tissue (Foerster and Altenburger, 1935 ; Walter, 1936 ; Scarff and Rahm, 1941).

Increased intracranial pressure can produce slow activity and there are probably at least two mechanisms. Williams (1939) clearly showed that cerebral oedema played a part by temporarily reducing the slow activity associated with cerebral tumours with intravenous hypertonic solutions; reduction of the C.S.F. pressure by lumbar puncture, however, had no such effect. Stewart (1941), in experiments on cats, found that slow activity could be produced only when there was active internal hydrocephalus causing tension in the cerebral white matter. Acute and chronic intracranial pressure without hydrocephalus did not produce slow activity. Scarff and Rahm (1941) described two patients with increased intracranial pressure secondary to craniopharyngiomata. Large slow waves were recorded from the surface of the distended dura overlying the middle frontal convolution; immediately following ventricular aspiration through a brain cannula, the slow waves disappeared.

A review of the records of 170 intracranial space-occupying lesions, confirmed by operation or necropsy (see Table), showed results similar to those

TABLE

E.E.G. IN 128 SUPRATENTORIAL INTR ACEREBRAL SPACEOCCUPYING LESIONS, EXCLUDING THOSE NEAR THIRD VENTRICLE

\begin{tabular}{|c|c|c|c|c|c|}
\hline Type & No. & Abnormal & Lateralized & Localized & Normal \\
\hline $\begin{array}{l}\text { Primary neo- } \\
\text { plasms } \\
\text { Abscesses } \\
\text { Metastases }\end{array}$ & $\begin{array}{l}87 \\
17 \\
24\end{array}$ & $\begin{array}{l}82 \\
17 \\
22\end{array}$ & $\begin{array}{l}79 \\
13 \\
14\end{array}$ & $\begin{array}{r}52 \\
10 \\
6\end{array}$ & $\frac{5}{2}$ \\
\hline Total & 128 & 121 & 106 & 68 & 7 \\
\hline
\end{tabular}

obtained by other workers (Cobb, 1950 ; Renfrew, Cameron, and Haggar, 1953). A few cases are of interest and help to illustrate certain general principles as well as some pitfalls in interpretation. The importance of oedema in supratentorial tumours and active ventricular dilatation in infratentorial tumours in the production of slow activity is stressed.

\section{Supratentorial Tumours}

Meningiomata, being slow-growing tumours, are usually considered to cause little abnormality in the E.E.G. However, two cases of basal meningiomata are reported which caused marked generalized cerebral oedema and high amplitude slow activity in the E.E.G.

Serial No. 2429. - A woman aged 48 had a meningioma of the right sphenoidal ridge. At necropsy the brain was elevated by the tumour and generally oedematous. The record was very abnormal with dominant slow activity at $2 \mathrm{c}$./s., which was chiefly frontal and rightsided. No definite focus was seen.

Serial No. 2263. - A woman aged 40 had a right olfactory groove meningioma found at operation. The first record showed dominant slow activity at 1 to $3 \mathrm{c}$./s. which was most marked on the right side. Following caffeine sodium benzoate injections, $2 \mathrm{ml}$. intramuscularly at six-hourly intervals for two days, the record was repeated. The slow activity was reduced in amount and maximal in the frontal region (Figs. 1 and 2).

The brain at necropsy in cases of cerebral metastases often shows marked oedema and this probably explains the gross generalized abnormality in the record. The oedema may spread across the midline via the commissures, especially the corpus callosum. In the early stages, however, even a secondary tumour may cause little or no abnormality. A patient with recent Jacksonian epilepsy associated with a primary bronchial carcinoma had a normal record. In another patient a small 
secondary carcinoma found at necropsy in the right frontal region caused no electroencephalographic abnormality.

A normal record in cases of supratentorial tumours is usually attributed to slow growth or to the site of origin. Three cases in the series are described below :-

Serial No. 2218. - A woman aged 32 with a history of three months' headaches and two months' vomiting showed on examination early papilloedema of the left disc and a weak left arm with pseudoathetosis and sensory changes. The E.E.G. was normal. Operation revealed a glioma in the right parietal region.

Serial No. 2803.-A man aged 39 had persistent headaches for four months, three attacks of sudden weakness of the legs without loss of consciousness, and a short history of vomiting. On examination there were no abnormal physical signs. The E.E.G. was normal. Necropsy three months later revealed an extensive glioblastoma in the left parieto-occipital region spreading across the midline via the corpus callosum.

Serial No. 764.-A woman aged 35 had, in October, 1947, a major fit, in 1949 Jacksonian fits involving the left arm, and in 1950 bilateral papilloedema. The E.E.G. was normal except for a little fast activity; no slow waves were seen. Operation revealed a right parietal astrocytoma.

It is noteworthy that not one of these tumours was a meningioma. In the following case, however, a meningioma caused minimal abnormality which can probably be attributed to the site of origin of the tumour.

Serial No. 8.-A man aged 44 had a right parasagittal meningioma at operation with one year's history of right-sided Jacksonian fits and minimal right-sided pyramidal signs. The E.E.G. showed excess theta activity at 6 to $7 \mathrm{c}$. $/ \mathrm{s}$. in the resting record.

Theta activity is usually attributed to deepseated lesions, but in this series was found in records of tumours at all sites. Diffuse theta activity suggests a lesion near the third ventricle (Walter and Dovey, 1944), and was found in the majority of tumours of the third ventricle, suprasellar tumours, and sellar tumours with abnormal neurological signs. But three out of five thalamic tumours caused ipsilateral delta activity.

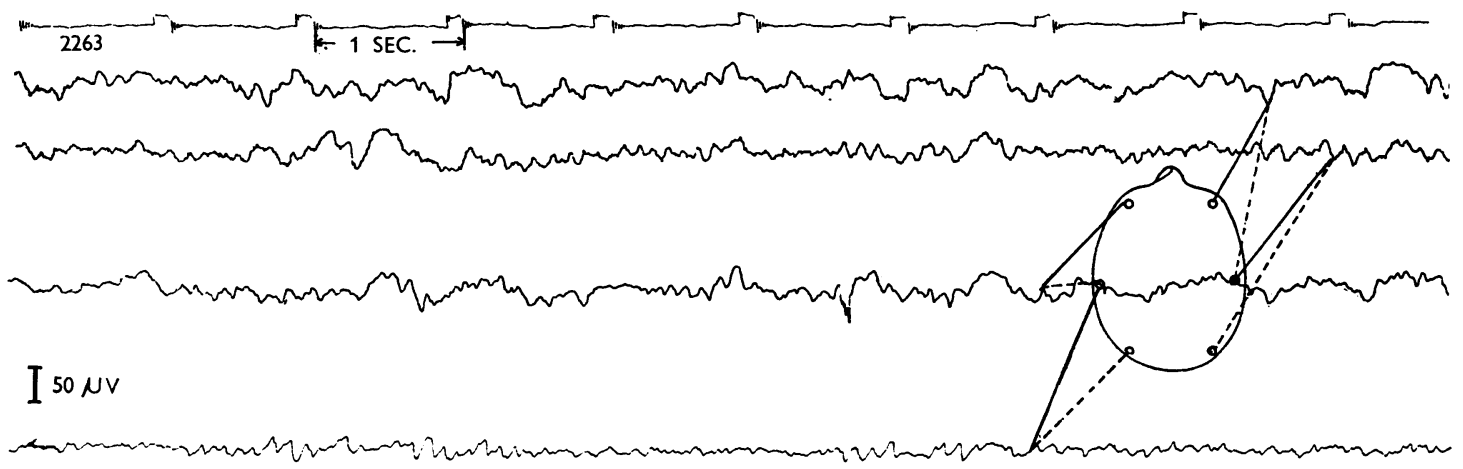

Fig. 1.-Serial No. 2263 : E.E.G. before caffeine sodium benzoate injection.

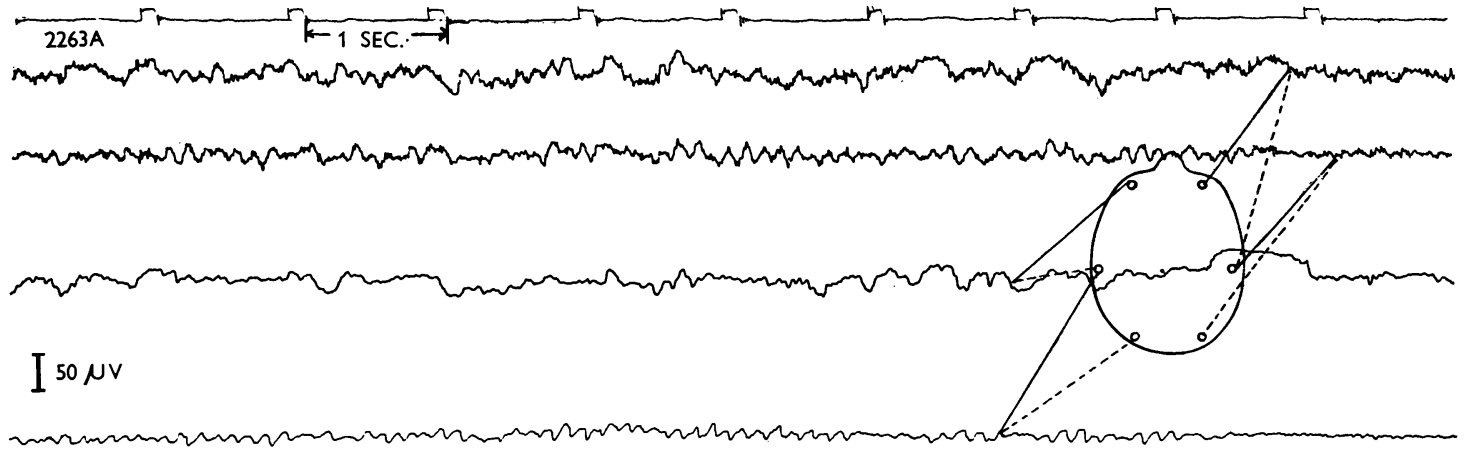

Fig. 2.-Serial No. 2263 : E.E.G. after caffeine sodium benzoate injection. Note the reduction in slow activity, especially in the right post-central region. 


\section{Infratentorial Tumours}

A normal record or a generalized abnormality is the usual finding in posterior fossa tumours. However, the following case showed a focal lesion, the mechanism of which was probably localized tension on white matter :-

Serial No. 2407.-A woman aged 53 had increasing mental deterioration and a few months' history of staggering. On examination she was demented and euphoric and had bilateral papilloedema. The clinical diagnosis was a frontal lobe tumour and the E.E.G. showed bilateral frontal high amplitude slow waves, more marked and occasionally focal on the left side. Ventriculography, however, showed hydrocephalus which was most marked in the frontal horns, and operation disclosed a cerebellar haemangioblastoma.

Three cases out of a total of 21 posterior fossa tumours (cerebellar tuberculoma, recurrence of a haemangioblastoma, and a medulloblastoma) showed an abnormality in one occipito-temporal region without clinical evidence to support such a localization; it may well be that the abnormality was due, at that time, to undue pressure on the white matter around the posterior horn. The tuberculoma was in the left cerebellar hemisphere and the electroencephalographic abnormality was right-sided. Bagchi, Lam, Kooi, and Bassett (1952) found similar contralateral changes in 25 out of 28 lesions of the cerebellar hemispheres, and this they attributed to interruption of physiological pathways. At least it seems unlikely that vascular changes due to venous obstruction or posterior cerebral artery compression could be the main factor.

The effect of caffeine sodium benzoate was tried on one patient with a cerebellar metastasis having diffuse 4 to $6 \mathrm{c}$./s. activity, with no change in the record.

\section{Subdural Lesions}

The E.E.G. in cases of subdural haematomata and hydromata is disappointing. There were five cases of subdural haematomata in the series; two were correctly localized on the basis of reduced alpha activity on the abnormal side, one also having excess delta activity on the side of the lesion. In two cases without alpha asymmetry the delta activity was on the contralateral side. In a generally abnormal record the greater theta activity was on the side of the haematoma. In four cases of subdural hydromata one record was normal, one was generally abnormal, and two showed greater delta activity on the contralateral side. In general, the records in subdural lesions are less abnormal than in intracerebral lesions for the same level of conscious- ness and clinical abnormality. In two cases where there was considerable abnormality in the E.E.G. there was also evidence to suggest recent cerebral contusion. Other authors have been successful in lateralizing subdural lesions in 70 to $75 \%$ of cases (Rodin, Bickford, and Svien, 1953 : Sullivan, Abbott, and Schwab, 1951). The chief features of value are focal delta activity and reduction of the alpha rhythm on the side of the haematoma. The generalized abnormality in the record in cases with tentorial herniation is probably due to anoxia affecting the brain-stem reticular substance. Experimental lesions in the brain-stem in cats produced high amplitude slow waves (Lindsley, Bowden, and Magoun, 1949). This may be the principal mechanism producing the diffuse abnormality in subdural haematomata (Rodin and others, 1953).

\section{Discussion}

There are two main mechanical factors in the production of high amplitude slow waves at a distance from the tumour. In supratentorial lesions this would chiefly be due to cerebral oedema, and in infratentorial lesions to active dilatation of the ventricles. In the former, caffeine sodium benzoat has been found clinically to be of great benefit in the relief of headaches due to increased intracraniab pressure. It is suggested that this may be due in part to reduction of cerebral oedema, possibly as a result of a diuretic action and possibly due to a change in cerebral blood flow. This drug is more easily administered and produces a more prolonged effect than do hypertonic solutions given intravenously.

Infiltrative supratentorial tumours, even when extensive, may cause so little mechanical or metabolic disturbances of normal cells that slow activity does not result. A normal record should not mislead the clinician in the presence of other strong evidence of tumour. This can be contrasted with compressing tumours such as meningiomata, abscesses, and cysts, which when actively expanding produce marked abnormality.

There is nothing original in the statement that cerebral oedema causes slow activity, but having seen many brains sectioned and compared the findings with the E.E.G. I have been impressed by the importance of this factor. The oedema need not be interstitial, and failure to respond to intravenous hypertonic solutions does not exclude its presence.

\section{Summary}

The importance of cerebral oedema in supratentorial tumours and active hydrocephalus in infra- 
tentorial tumours causing slow activity in the E.E.G. is stressed.

Infiltrating supratentorial tumours may cause little mechanical distortion of normal cells and the E.E.G. may be normal. Actively expanding tumours cause marked slow activity.

The E.E.G. in subdural lesions was of little lateralizing value in this series.

I wish to thank Dr. R. S. Allison and Dr. H. Hilton Stewart, of the Department of Neurology, and Mr. C. A. Calvert and Mr. A. R. Taylor, of the Department of Neurosurgery, of the Royal Victoria Hospital, Belfast, for permission to use the clinical notes of patients under their care; also I would like to thank Professor J. H. Biggart, of the Institute of Pathology, the Queen's University, Belfast, for permission to publish pathological findings. Mr. R. J. Luke kindly read and criticized this paper.

\section{REFERENCES}

Bagchi, B. K., Lam, R. L., Kooi, K. A., and Bassett, R. C. (1952). Electroenceph. clin. Neurophysiol., 4, 23.

Berger, H. (1931). Arch. Psvchiat. Nervenkr., 94, 16.

Cobb,'W. A. (1950). In Electroencephalography, ed. Hill, D., and Parr, G., p. 273. Macdonald, London.

Foerster, O., and Altenburger, H. (1935). Dtsch. Z. Nervenheilk., $135,277$.

Lindsley, D. B., Bowden, J. W., and Magoun, H. W. (1949). Electroenceph. clin. Neurophysiol., 1, 475.

Renfrew, S. Cameron, J. H., and Haggar, I. L. (1953), Brain, 76, 92.

Rodin, E. A., Bickford, R. G., and Svien, H. J. (1953). Arch. Neurol. Psvchiat., Chicago, 69, 743.

Scarff, J. E., and Rahm, W. E. (1941). J. Neurophysiol., 4, 418.

Stewart, W. A. (1941). Bull. Johns Hopk. Hosp., 69, 240.

Sullivan, J. F., Abbott, J. A., and Schwab, R. S., (1951). Electroenceph. clin. Neurophysiol., 3,131.

Walter, W. G. (1936). Lancet, 2, 305.

, and Dovey, V. J. (1944). Journal of Neurology, Neurosurgery

and Psychiatry, 7, 57.
Williams, D. (1939). Brain, 62, 321.

\section{THE NOVEMBER (1954) ISSUE}

The November (1954) issue contains the following papers :-

Focal Cerebral and Cerebellar Atrophy in a Human Subject Due to Organic Mercury Compounds. Donald Hunter and Dorothy S. Russell.

The Absorption and Excretion of Radiocopper in Hepato-lenticular Degeneration (Wilson's Disease). W. B. Matthews. Adrenaline and Noradrenaline in Cerebrospinal Fluid. H. Weil-Malherbe and D. W. Liddell.

The Treatment of Manic Psychoses by the Administration of Lithium Salts. M. Schou, N. Juel-Nielsen, E. Strömgren, and $\mathbf{H}$. Voldby.

The Sequelae and Short-term Prognosis of Attempted Suicide. The Results of a One-year Follow-up of 200 Cases.

I. R. C. Batchelor and Margaret B. Napier.

The Effect of Temporal Lobectomy upon Two Cases of an Unusual Form of Mental Deficiency. D. W. Liddell and D. W. C. Northfield.

Pathological Findings in Temporal Lobe Epilepsy. Alfred Meyer, Murray A. Falconer, and Elisabeth Beck.

The Reticular Perivascular Tissue of the Central Nervous System. J. W. Millen and D. H. M. Woollam.

Case Report : Prenatal Occlusion of the Internal Carotid Artery. R. M. Clark and Eric A. Linell.

Case Report : Hairy Teratomatous Cyst in the Occipito-cerebellar Region. S. Obrador.

Periarteritic Lesions of the Carotid Siphon with the Clinical Features of a Carotid Infraclinoidal Aneurysm.

Eduardo Tolosa.

Intramedullary Spinal Abscess. J. E. M. Dutton and G. L. Alexander.

A number of copies are still available and may be obtained from the Publishing Manager, British Medical Association, Tavistock Square, W.C.1, price 12s. 6d. 